\title{
Phylogeny of Twenty Thermus Isolates Constructed from 16S rRNA Gene Sequence Data
}

\author{
D. J. SAUL, ${ }^{1}$ A. G. RODRIGO, ${ }^{2}$ R. A. REEVES, ${ }^{1}$ L. C. WILLIAMS,${ }^{1}$ K. M. BORGES,${ }^{3}$ \\ H. W. MORGAN, ${ }^{4}$ AND P. L. BERGQUIST ${ }^{1 *}$ \\ Molecular Genetics and Microbiology ${ }^{1}$ and Experimental Biology, ${ }^{2}$ School of Biological Sciences, University \\ of Auckland, Private Bag 92019, Auckland, and Thermophile Genetics, University of Waikato, Hamilton, ${ }^{4}$ \\ New Zealand, and Center for Marine Biotechnology, Baltimore, Maryland $21202^{3}$
}

\begin{abstract}
The sequences of the 16S rRNA genes of 20 Thermus isolates were determined to a high fidelity by using automated DNA sequencing and fluorescent-dye-labelled primers. The strains tested included members of the three validly named Thermus species and representatives of major taxonomic clusters defined previously for this genus. The parsimony method was used to reconstruct the phylogeny of the strains from the aligned sequences, and a bootstrap analysis revealed a number of well-supported clades. Our results are not consistent with groupings inferred from numerical taxonomy data but support the conjecture that the genus Thermus contains more species than the three currently recognized species.
\end{abstract}

Since the original description of the genus Thermus by Brock and Freeze (4), the ubiquitous nature of members of this taxon has been demonstrated by the ready isolation of strains from neutral-pH thermal areas around the world (reviewed in reference 48). The genus Thermus represents a deep eubacterial branch (16) and contains three validly named species: Thermus aquaticus (4), Thermus ruber (26), and Thermus filiformis (20). Many other Thermus isolates have been described in some detail but have not yet been validly named; the taxonomy of the genus is still incomplete. While there is general agreement that $T$. ruber and $T$. aquaticus are taxonomically and phylogenetically distinct (17), it is still unclear whether the yellow-pigmented isolates that grow at $70^{\circ} \mathrm{C}$ constitute a single species or more than one species. In a numerical taxonomic study Hudson et al. (21) discerned eight species groups which were separated at a simple matching coefficient value of $65 \%$, while Williams (47) suggested that there are at least four genospecies on the basis of DNA-DNA hybridization data and other properties. In both cases there were strong indications that strains isolated from the same thermal region shared common properties and grouped together. A comparison of results is difficult because different strains have been used in different studies.

In this study the sequences of the 16S rRNA genes of 20 Thermus strains were determined by using a procedure developed specifically to provide high-fidelity data with an automated DNA sequencer, and the aligned sequences were subjected to phylogenetic analysis. The complete $16 \mathrm{~S}$ rRNA gene sequence of "Thermus thermophilus" HB8 (29) and a partial sequence of $T$. aquaticus (45) were available from other sources, but the results described below were derived from our own sequence versions. The 20 strains included representatives of the major clusters defined in the study of Hudson et al. (21) and the three validly named species, as well as two "T. thermophilus" strains (HB8 and HB27) and "Thermus flavus."

Phylogenetic systematics is a two-stage process. The first stage is the estimation of a phylogenetic tree, and for this we used aligned sequence data and reconstructed the phylogeny by using the criterion of maximum parsimony (44). The

\footnotetext{
* Corresponding author.
}

second stage is the translation of the phylogenetic tree into a classification; at the present time there are two methods available for doing this, and they have been described in full by Wiley (46). One approach is the method of "subordination," in which every nested clade is given a new taxonomic rank. The problem with this procedure is that depending on the number of taxa and the topology of the phylogenetic tree, the number of ranks can exceed practical limits. The method used in our analysis is the "phyletic sequencing" method, in which all clades that arise from the same major branch or "trunk" of a phylogenetic tree are recognized as having the same taxonomic rank. This method circumvents the problem of having too many ranks, and as a result, the method has been adopted as the de facto standard.

Our results indicate that there is significant cladistic structure in the data with statistically supported clades. Although these clades largely disagree with the numerical classification data (21), their presence supports the suggestion that the genus Thermus may contain more species than the three currently recognized species.

\section{MATERIALS AND METHODS}

Design of oligonucleotide primers. The sequences of the $16 \mathrm{~S}$ rRNA genes of eubacteria belonging to a variety of genera were aligned by using the multiple-sequence alignment program PILEUP (13). The genes chosen for alignment were from Escherichia coli (10), "T. thermophilus" (29), Bacillus subtilis (15), Clostridium perfringens (14), and Anacystis nidulans (25). The primer sequences used were based on regions with high levels of homology which were optimally spaced for DNA sequencing (Table 1 ).

Bacterial strains, media, and culture conditions. The Thermus strains used in this study are listed in Table 2 . M13 mp10 recombinant phages were grown in E. coli JM101 (49) which was grown in YT broth $(0.8 \%$ Bacto Tryptone, $0.5 \%$ yeast extract, $0.5 \% \mathrm{NaCl}$ ). The Thermus species were grown at temperatures appropriate for each isolate (Table 2) in 162 salts (6) supplemented with $0.3 \%$ Bacto Tryptone and $0.3 \%$ yeast extract. Solid media contained $2.7 \%$ Davis agar. For M13 recombinants, 5-bromo-4-chloro-3-indoxyl- $\beta$-D-galactoside and isopropyl-1-thio- $\beta$-D-galactopyranoside were added to solid YT media to final concentrations of 20 and 4 $\mu \mathrm{g} / \mathrm{ml}$, respectively. 
TABLE 1. Positions and sequences of primers used for PCR isolation and sequencing of Thermus 16S rRNA genes

\begin{tabular}{|c|c|c|c|}
\hline Primer & Strand & Position $^{a}$ & Sequence \\
\hline PCR1 & $\mathrm{F}$ & $(1 \rightarrow 21)$ & TTGTTGGAGAGTTTGATCCTG \\
\hline PCR2 & $\mathbf{R}$ & $(1519 \rightarrow 1494)$ & AAAGGAGGTGATCCAGCCGCACCTTC \\
\hline RNA1 & $\mathrm{F}$ & $337 \rightarrow 356$ & ACTCCTACGGGAGGCAGCAG \\
\hline RNA2 & $\mathbf{F}$ & $516 \rightarrow 535$ & GCCAGCAGCCGCGGTAATAC \\
\hline RNA3 & $\mathbf{F}$ & $784 \rightarrow 805$ & GGATTAGATACCC $(G / T)(G / T)$ GTAGTCC \\
\hline RNA4 & $\mathbf{F}$ & $1086 \rightarrow 1105$ & GGGTTAAGTCCCGCAACGAG \\
\hline RNA5 & $\mathbf{R}$ & $356 \rightarrow 337$ & CTGCTGCCTCCCGTAGGAGT \\
\hline RNA6 & $\mathbf{R}$ & $535 \rightarrow 516$ & GTATTACCGCGGCTGCTGGC \\
\hline RNA7 & $\mathrm{R}$ & $805 \rightarrow 784$ & GGACTAC (C/A) (C/A)GGGTATCTAATCC \\
\hline RNA8 & $\mathrm{R}$ & $1105 \rightarrow 1086$ & CTCGTTGCGGGACTTAACCC \\
\hline
\end{tabular}

a The positions of primers RNA1 to RNA8 are the coordinates of the primers on the 16S rRNA sequence of $E$. coli (10). The sequences of PCR1 and PCR2 were derived from the 16S rRNA sequence of "T. thermophilus" (29), and the positions of these primers are the positions on the gene of this organism.

Genomic DNA preparation, PCR isolation, and cloning of $16 S$ rRNA genes. Total cellular DNA was isolated from 30 - to 50-ml Thermus cultures by using a minor modification of the method of Saito and Miura (36). Polymerase chain reactions (PCR) for 16S rRNA genes were carried out by using $10 \mathrm{pmol}$ of primers PCR1 and PCR2 (Table 1) and $0.2 \mathrm{U}$ of Taq polymerase (AmpliTaq; Cetus Corp.) in 50- $\mu$ l portions of a buffer containing deoxynucleoside triphosphates at concentrations of $250 \mu \mathrm{M}, 2.5 \mathrm{mM} \mathrm{MgCl}, 10 \mathrm{mM}$ Tris (pH 8.8), 50 $\mathrm{mM} \mathrm{KCl}$, and $0.001 \%$ gelatin. The following thermal cycle was used for 30 cycles: $94^{\circ} \mathrm{C}$ for $1 \mathrm{~min}, 57^{\circ} \mathrm{C}$ for $1 \mathrm{~min}$, and $72^{\circ} \mathrm{C}$ for $4 \mathrm{~min}$. Each amplified fragment was "polished" and phosphorylated by using standard techniques described by Maniatis et al. (27). The fragments were gel purified on $1 \%$ agarose (acetate) gels, removed from the agarose with GeneClean (Bio 101, San Diego, Calif.), extracted once with phenol, and inserted into SmaI-cut M13 mp10 (28) by using T4 DNA ligase.
Synthesis and dye labelling of oligonucleotides. All oligonucleotides were synthesized with an Applied Biosystems model 392 synthesizer by using the cyanoethyl phosphoramadite method with Aminolink 2 attached at the 5' terminus (1a). Four 10-nmol portions of each oligonucleotide were labelled with $0.2-\mathrm{mg}$ portions of the four fluorescent dyes used by Applied Biosystems automated sequencers under the conditions specified by the manufacturers. Excess label was removed from the labelled oligonucleotides by precipitation in ethanol. Pellets were extensively washed, dried, and finally resuspended in $200 \mu \mathrm{l}$ of $10 \mathrm{mM}$ Tris $-1 \mathrm{mM}$

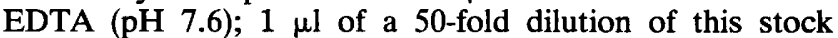
solution was found to be close to the correct concentration for sequencing reactions, although some optimization was occasionally required.

DNA sequencing. Sequencing reactions were carried out by using an ABI Catalyst 800 robotic workstation and an ABI model $373 \mathrm{~A}$ automated sequencer. In general, the

TABLE 2. Bacterial isolates used in this study

\begin{tabular}{|c|c|c|c|c|c|c|}
\hline Organism & Abbreviation $^{a}$ & Source & $\begin{array}{c}\text { Culture } \\
\text { collection no. }\end{array}$ & $\begin{array}{l}\text { Growth } \\
\text { temp } \\
\left({ }^{\circ} \mathrm{C}\right)\end{array}$ & $\begin{array}{l}\text { Accession } \\
\text { no. }{ }^{c}\end{array}$ & $\begin{array}{l}\text { Refer- } \\
\text { ence }\end{array}$ \\
\hline "T. thermophilus" HB8 & HB8 & Hot spring, Japan & ATCC 27634 & 75 & X07998 & 30 \\
\hline "T. thermophilus"' HB27 & HB27 & Hot spring, Japan & & 70 & L09659 & 24 \\
\hline "T. flavus" AT-62 & "T. flavus" & Japan & ATCC 33923 & 75 & L09660 & 35 \\
\hline T. ruber & T. ruber & Kamchatka, USSR & DSM 1279 & 50 & L09672 & 26 \\
\hline T. aquaticus YT-1 & T. aquaticus & Yellowstone Park, Wyo. & ATCC 25104 & 70 & L09663 & 4 \\
\hline Thermus sp. strain NMX2 A.1 & NMX2 & Jemez, N. Mex. & TG 263 & 70 & L09661 & 18 \\
\hline Thermus sp. strain YSPID A.1 & YSPID & $\begin{array}{l}\text { Octopus Spring, Yellowstone Park, } \\
\text { Wyo. }\end{array}$ & TG 287 & 70 & L10070 & 18 \\
\hline Thermus sp. strain ZHGI A.1 & ZHGI & Haegindi, Iceland & TG 201 & 70 & L09664 & 18 \\
\hline Thermus sp. strain ZFI A.2 & ZFI & Fludir, Iceland & TG 166 & 70 & L09662 & 18 \\
\hline Thermus sp. strain ZHGIB A.4 & ZHGIB & Haegindi, Iceland & TG 218 & 70 & L10071 & 18 \\
\hline Thermus sp. strain Fiji3 A.1 & Fiji3 & Savu Savu Beach, Fiji & TG 113 & 70 & L10067 & 18 \\
\hline Thermus sp. strain Rt41A & Rt41A & Kuirau Park, Rotorua, New Zealand & TG 52 & 72 & L09669 & 32 \\
\hline$T$. filiformis & T. filiformis & Waimangu, New Zealand & TG 80 & 70 & L09667 & 20 \\
\hline Thermus sp. strain Tok3 A.1 & Tok3 & Tokaanu, New Zealand & TG 49 & 75 & L10069 & 40 \\
\hline Thermus sp. strain Tok8 A.1 & Tok8 & Tokaanu, New Zealand & TG 12 & 72 & L09666 & 19 \\
\hline Thermus sp. strain Tok20 A.1 & Tok20 & Tokaanu, New Zealand & TG 119 & 70 & L09665 & 19 \\
\hline Thermus sp. strain W28 & W28 & Waimangu, New Zealand & TG 29 & 70 & L10068 & 18 \\
\hline Thermus sp. strain OK6 A.1 & OK6 & Orakei Korako, New Zealand & TG 50 & 70 & L09668 & 23 \\
\hline Thermus sp. strain T351 & $\mathrm{T} 351$ & Whakarewarewa, New Zealand & TG 8 & 72 & L09671 & 18 \\
\hline Thermus sp. strain HS A.1 & HS1 & Hamner Springs, New Zealand & TG 271 & 70 & L09670 & 18 \\
\hline Thermotoga maritima MSB-8 & Th. maritima & Naples, Italy & DSM 3109 & 85 & M21774 & 1 \\
\hline
\end{tabular}

a Abbreviations used in Fig. 1.

b ATCC, American Type Culture Collection, Rockville, Md.; DSM, Deutsche Sammlung von Mikroorganismen, Braunschweig, Germany; TG, Thermophile Group, University of Waikato, Hamilton, New Zealand.

${ }^{c}$ GenBank accession number of the 16S rRNA gene sequence. 
mobility shift file provided by Applied Biosystems for sequencing primer SP6 worked well enough for the home-made dye primers, but in some cases, existing files proved to be inadequate and we required Applied Biosystems to generate new mobility shift files specific for individual primers. The length of sequence obtained varied for each primer, but the methods which we used gave sufficient data to provide accurate, overlapping sequences of both strands of the genes. The sequences of the forward and reverse strands were generated from separate PCR isolates because the use of two or more isolates, rather than a single recombinant, highlighted errors caused by misincorporation of bases during the PCR. Any discrepancies in the forward and reverse sequences were resolved by sequencing additional recombinants. However, on a few occasions, a base could not be resolved, and we assumed that this was due to base differences between the two genes present on the Thermus genome (see below). In these instances, a sequence uncertainty code was used. The 5'- and 3 '-terminal sequences corresponding to the PCR primers cannot be considered a reliable representation of the original genome because of the possibility of slight differences between the primers and their binding sites. These bases were not included in the computer analysis or the sequences submitted to GenBank.

Phylogenetic methods. The full-length sequences were constructed by using the GCG (Wisconsin) package of Devereux et al. (8) run on a Silicon Graphics 4D-30 workstation. Sequences were aligned by the algorithm PILEUP (13) with a low gap weight, and the $16 \mathrm{~S}$ rRNA sequence of Thermotoga maritima (1) was included as an outgroup sequence so that the phylogenetic tree could be rooted. Because of the high levels of similarity among the Thermus sequences, the choice of alignment was clear-cut, and no corrections for secondary structure were required. Minor modifications were made for alignment of the sequence of the outgroup organism, Thermotoga maritima. Aligned sequences were analyzed by using the computer program PAUP 3.0 (43), which estimates a phylogenetic tree by using the criterion of maximum parsimony. All 1,515 sites were used, and gaps were treated as missing data. The tree bisection-reconnection branch-swapping option was used to search for the most parsimonious tree. A total of 100 bootstrapped trees were sampled (11) to determine a measure of the support for each clade on the tree. The neighbor-joining method of phylogenetic reconstruction (37) was also applied to the data by using the programs DNADIST (to generate evolutionary distances) and NEIGHBOR (to construct the neighborjoining tree), which form part of the PHYLIP, version 3.5, computer package (12). Neighbor-joining bootstrapping was also performed.

Nucleotide sequence accession numbers. The nucleotide sequence accession numbers for the isolates which we studied are shown in Table 2.

\section{RESULTS AND DISCUSSION}

DNA sequencing. A number of methods are available for sequencing 16S rRNA. However, with closely related organisms, sequencing errors can lead to quite major changes in the assessed phylogeny (5). Direct sequencing of rRNA by using reverse transcriptase has been used in a number of studies, including one examining Thermus strains (2). The approach taken in this study was to sequence one of the two 16S rRNA genes isolated by the PCR. Several methods for automated sequencing of 16S rRNA genes were tested for reliability. An obvious technique was to sequence PCR products directly by using internal primers and dye-labelled terminators. However, this method has inherent problems because of the nature of the 16S rRNA gene sequence. rRNA has a strong secondary structure, and after denaturation single-stranded templates derived from rRNA genes mimic portions of the secondary structure to form hairpins which inhibit polymerase extension. One solution is to use elevated reaction temperatures and a heat-stable enzyme such as Taq polymerase, but unfortunately, dye terminator chemistry is presently limited to reaction temperatures of less than $65^{\circ} \mathrm{C}$ (below the temperature optimum of Taq polymerase) because at higher temperatures the enzyme has difficulty incorporating dideoxynucleoside triphosphate terminators linked to a dye ligand. Although a temperature of $65^{\circ} \mathrm{C}$ is considerably higher than the temperatures required by mesophilic enzymes, secondary structure within templates can still be a problem. Denaturing agents such as dimethyl sulfoxide can alleviate the secondary structure problem to some extent, but in our experiments the results were still of insufficient quality for comparisons between such similar genes. The sequences reported in this paper were obtained by using rRNA-specific dye-labelled primers and standard dideoxynucleoside triphosphates, which allowed reactions to be performed at $70^{\circ} \mathrm{C}$; at this temperature, the problem of secondary structure is greatly reduced. A further improvement in sequence quality was gained by cloning all PCR products in M13 vectors. This provided a more consistent sequencing template than purified PCR fragments.

Comparison of two 16S rRNA genes in "T. thermophilus" HB8. "T. thermophilus" has two 16S rRNA genes which have been mapped to separate NdeI restriction fragments of the genome (3). Consequently, it was necessary to confirm that the two genes have identical or very similar DNA sequences. The two genes of " $T$. thermophilus" HB8 were individually isolated by cutting genomic DNA with NdeI, and fragments $1(706 \mathrm{~kb})$ and $8 \mathrm{~b}(30 \mathrm{~kb})(3)$ were separated by pulsed-field gel electrophoresis. A PCR was performed with DNA present in cores removed from the agarose gel, and 500 -bp sequences at the $5^{\prime}$ and $3^{\prime}$ ends of the two genes were obtained and compared. There were no detectable differences between the two genes in these regions (data not shown), and as these sequences cover much of the gene, including five variable regions, we inferred that it was acceptable to isolate either of the two genes at random by performing a PCR with total genomic DNA. The complete sequence of the 16S rRNA gene of $\mathrm{HB} 8$ has been published previously by Murzina et al. (29). However, Hartmann et al. (16) observed two discrepancies in their data, one in the V6 region and the other, a missing $\mathrm{AC}$, at positions 1245 and 1246 ( $E$. coli numbering). The sequence obtained by us is in accord with the results of Hartmann et al., and this version was used in our analyses.

Phylogenetic analysis. Table 3 shows the pairwise differences between the sequences, and from these data two most parsimonious trees were identified, each with a length of 682 and a consistency index of 0.603 . The strict consensus tree with the percentage of bootstrapped trees supporting each clade is shown in Fig. 1. There are no substantial differences between the results obtained by the neighbour-joining method and the results obtained by using parsimony analysis, and so the neighbor-joining data are not given in this paper.

Although there appears to be superficial agreement between the clades of the phylogenetic tree and the clusters of Hudson et al. (21), inconsistencies exist (namely, the poly- 


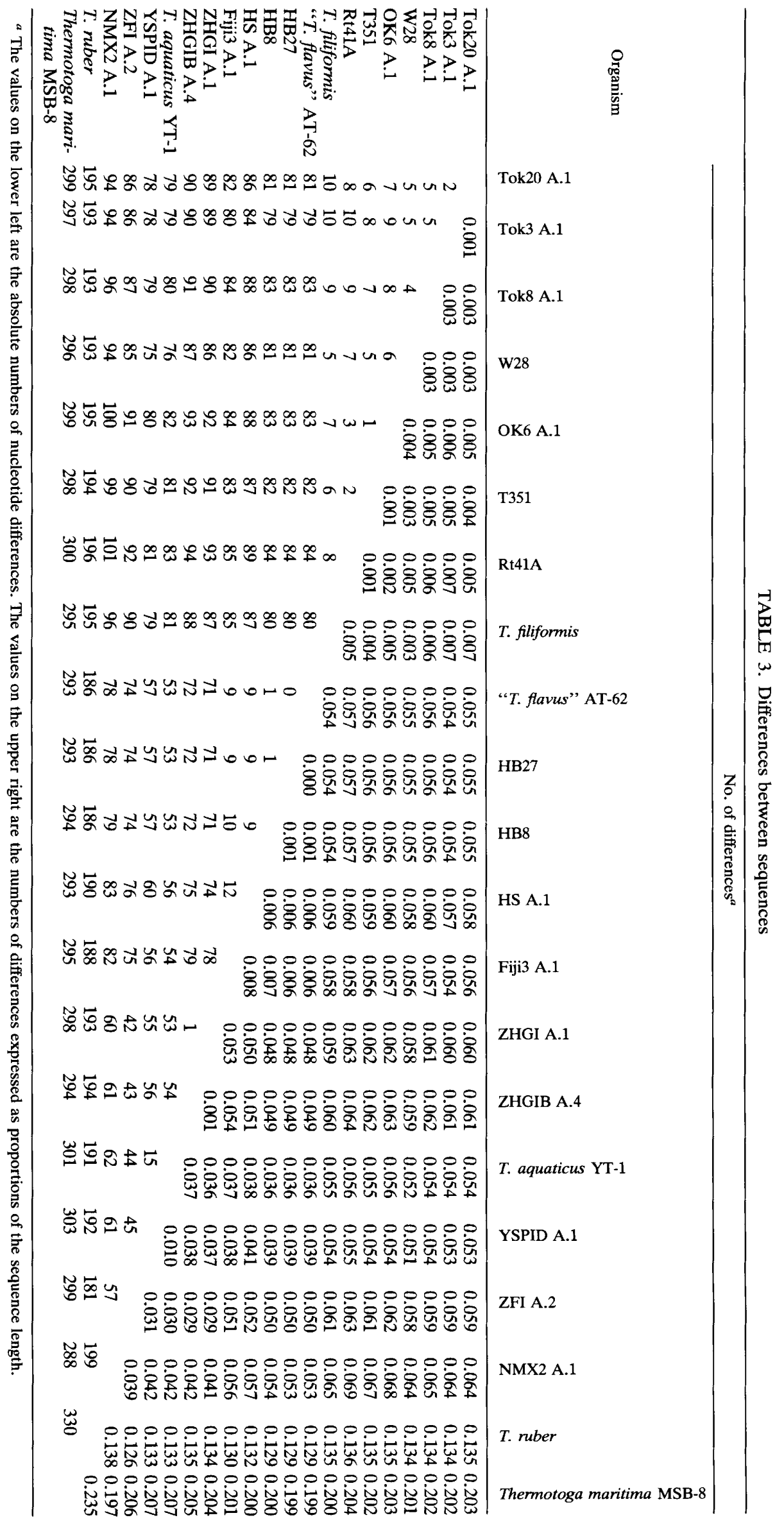




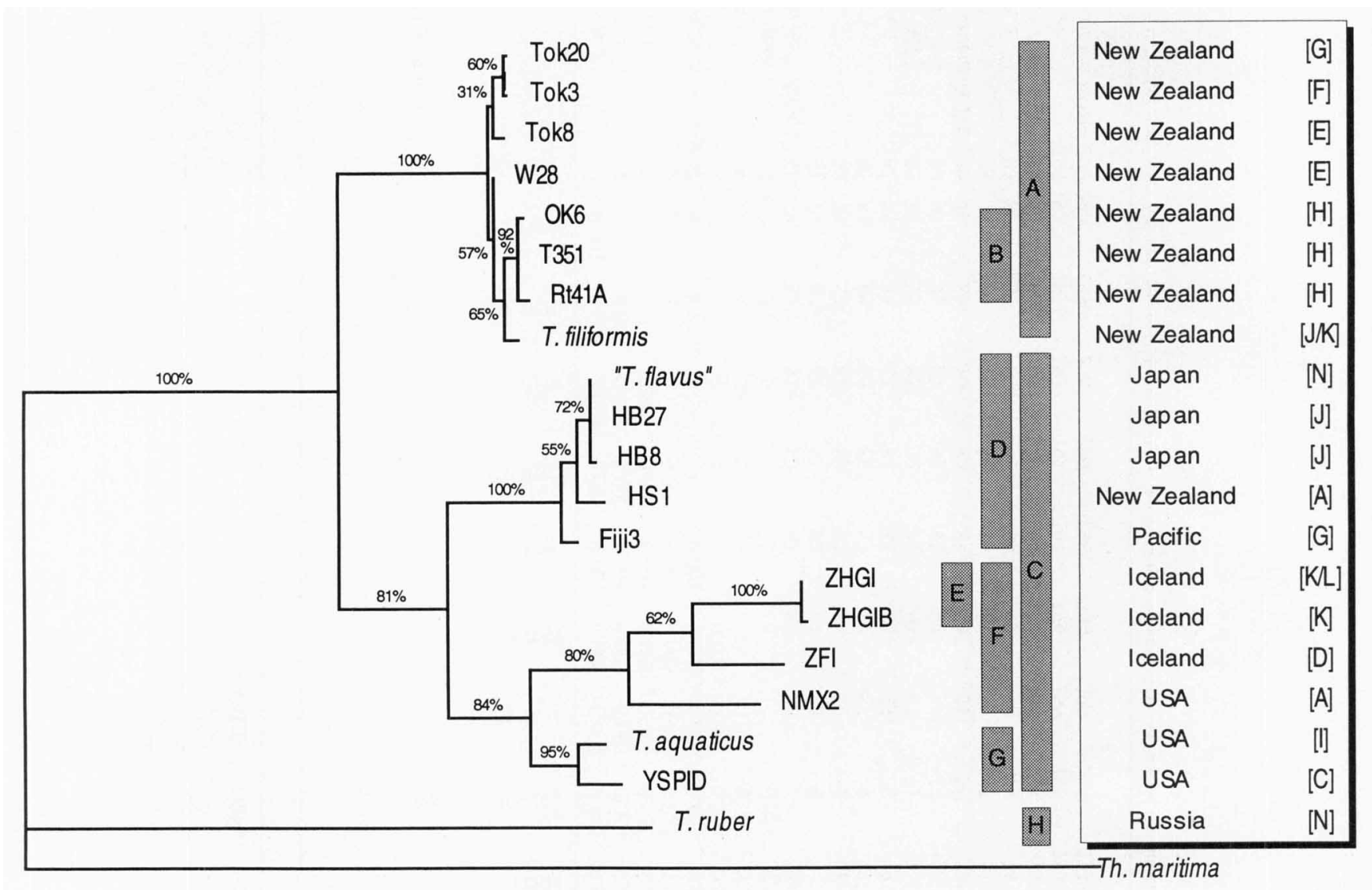

$\longrightarrow$

FIG. 1. Strict consensus phylogenetic tree constructed from two most parsimonious trees. The scale bar represents an expected nucleotide substitution rate of 0.01 change per site. The values on the branches indicate the levels of support derived from 100 bootstrapped trees. The shaded boxes delineate clades supported by more than $80 \%$ of the bootstrapped trees. Also included are the geographic origins of the isolates and the cluster assignments made by Hudson et al. (21) (letters in brackets). For abbreviations see Table 2.

phyly of Tok20 A.1 and Fiji3 A.1 [clustered in group G by Hudson and coworkers], the polyphyly of "T. flavus" and $T$. ruber [clustered in group N], the polyphyly of HS A.I and NMX2 A.1 [clustered in group A], and the paraphyly of Tok8 A.1 and W28 [group E]). Such a result is not unexpected; phenotypic markers do not necessarily provide phylogenetic conclusions, and in some cases the groups are represented by only one or two sequences which may not be representative. The degree of correlation between the available sequence data and the clusters of Hudson et al. was tested by constraining taxa grouped in the same clusters to monophyly and then calculating the lengths of the trees generated. Six constrained trees were found, each 104 steps longer than the most parsimonious trees, implying that if we were to accept the hypothesis that the clusters defined by Hudson et al. represent monophyletic assemblages, we would have to postulate 104 more homoplastic base substitution events (parallelisms, convergences, or reversals) than is necessary in the evolution of the 16S rRNA sequences. As a consequence, there is good evidence that these clusters do not represent phylogenetic groups.

There are clear and well-supported differences between the clades on the tree, which is evident from the bootstrap values obtained. Felsenstein (11) suggested that the monophyly of a clade should be accepted only if the clade occurs in more than $95 \%$ of the bootstrapped trees. Other workers (for example, Sanderson [38]) have argued that the 95\% value is too conservative; by calibrating the bootstrap test of monophyly for four taxa, Rodrigo (33) noted that a value of $80 \%$ may be more appropriate. If a critical value of $80 \%$ is used, the clades shown in Fig. 1 emerge as being significantly supported. Three major clades (clades $\mathrm{A}, \mathrm{C}$, and $\mathrm{H}$ ) each contain one of the currently recognized species, thus allowing for the possibility that these clades and the strains that they contain delimit the nominal species. However, it is possible to split clades $A$ and $C$ further. For example, according to one method of translating a phylogenetic tree into a classification (the method of phyletic sequencing [46]), the following clades may be recognized as species: clades A, $D, F$, and G. Because the clades are significantly supported by the bootstrap, we believe that there is initial evidence to indicate that the Thermus isolates used in this study represent more than three species.

The phylogenetic tree is consistent with the results of several other reports $(2,17,41)$ in separating $T$. ruber from T. aquaticus (and by implication from other yellow-pigmented high-temperature Thermus strains). The validity of the $T$. ruber genospecies was established and supported by good phenotypic markers (41), although recently the membrane lipid composition of $T$. ruber was shown to be very similar to that of $T$. aquaticus (9). Williams (47), using DNA-DNA homology data, and Donato et al. (9), using lipid 
analysis data, concluded that $T$. aquaticus and " $T$. thermophilus" are distinct genospecies. These organisms are clearly separated in the numerical taxonomies of Hudson et al. (21) and Santos et al. (39) and in our phylogenetic tree.

Clade A and particularly subclade B in this study conform fairly closely to clusters $\mathrm{H}$ and $\mathrm{E}$ of Hudson et al. (21). However, the morphology of $T$. filiformis, a validly named species and a member of clade $A$, is not typical of the morphology of other organisms in the clade. The most obvious morphological characteristic of $T$. filiformis is its ability to form filaments on basal CMD medium containing 3 $\mathrm{g}$ of Trypticase per liter and yeast extract. Other Thermus species can be induced to form filaments, but only in the presence of high concentrations of glycine and other amino acids. The levels used in the induction experiments are unlikely to be found in the native habitat, and Janssen et al. (22) suggested that $T$. filiformis forms filaments by a different mechanism than other Thermus species. In addition, $T$. filiformis has a unique membrane lipid composition (9) and remained unclustered in the numerical taxonomy of Hudson et al. Therefore, this organism may not be the organism of choice to typify this genospecies.

There is an apparent geographical correlation within the clades which could be tested by identifying strains in their native environments. A strain present in a pool may remain undetected because it is selectively removed during enrichment, and indeed, it could be argued that the geographical grouping seen in the data may be an artifact of different approaches to enrichment. The sequence data should be useful for designing clade-specific probes as each major clade has distinctive sequence motifs that are located in definite regions within the 16S rRNA genes (data not shown). By using fluorescent-dye-labelled oligonucleotide probes capable of hybridizing with these variable regions, it should be possible to categorize individual Thermus cells and to examine the diversity and distribution of these organisms in nonenriched samples $(7,42)$.

The phylogeny inferred from the 16S rRNA data and the degree of bootstrap support for some of the major clades provide some evidence for the conjecture that there are more than three Thermus species. However, as other authors have argued $(31,34)$, evolutionary trees estimated from a single gene should be treated with caution. The degree to which lateral transfer of genetic material has occurred and the effects of ancestral polymorphism and selection cannot be readily estimated. It is only with the application of different data that we can corroborate or disprove the results of the phylogenetic analysis described above. With this aim in mind, we are sequencing the genes for Thermus DNA polymerases and DNA ligases, and in addition, a collaborative project is under way which will combine phenotypic, molecular, and DNA sequence data to provide a definitive taxonomy of the genus Thermus.

\section{ACKNOWLEDGMENTS}

This work was supported in part by a grant from the University of Auckland Research Committee and by Pacific Enzymes Ltd.

\section{REFERENCES}

1. Achenbach-Richter, L., R. Gupta, K. O. Stetter, and C. R. Woese. 1987. Were the original eubacteria thermophiles? Syst. Appl. Microbiol. 9:34-39.

1a.Applied Biosystems. 1988. DNA synthesizer user bulletin 49 . Applied Biosystems, Foster City, Calif.

2. Bateson, M. M., K. J. Thibault, and D. M. Ward. 1990 Comparative analysis of $16 \mathrm{~S}$ ribosomal RNA sequences of
Thermus species. Syst. Appl. Microbiol. 13:8-13.

3. Borges, K. M., and P. L. Bergquist. 1993. Genomic restriction map of the extremely thermophilic bacterium Thermus thermophilus HB8. J. Bacteriol. 175:103-110.

4. Brock, T. D., and H. Freeze. 1969. Thermus aquaticus gen. n. and sp. n., a non-sporulating extreme thermophile. J. Bacteriol. 98:289-297.

5. Clark, A. G., and T. S. Whittam. 1992. Sequencing errors and molecular evolution analysis. Mol. Biol. Evol. 4:744-752.

6. Degryse, E., N. Glansdorff, and A. Pierard. 1978. A comparative analysis of extreme thermophilic bacteria belonging to the genus Thermus. Arch. Microbiol. 117:189-196.

7. DeLong, E. F., G. S. Wickham, and N. R. Pace. 1989. Phylogenetic stains: ribosomal RNA-based probes for the identification of single cells. Science 243:1360-1362.

8. Devereux, J., P. Haeberli, and O. Smithies. 1990. A comprehensive set of sequence analysis programs for the VAX. Nucleic Acids Res. 12:387-395.

9. Donato, M. M., E. A. Seleiro, and M. S. Da Costa. 1990. Polar lipid and fatty acid composition of strains of the genus Thermus. Syst. Appl. Microbiol. 13:234-239.

10. Ehresmann, C., P. Stiegler, P. Fellner, and J.-P. Ebel. 1972. The determination of the primary structure of the $16 \mathrm{~S}$ ribosomal RNA of Escherichia coli. II. Nucleotide sequences of products from partial enzymatic hydrolysis. Biochimie 54:901-967.

11. Felsenstein, J. 1985. Confidence limits on phylogeny and approach using the bootstrap. Evolution 39:783-791.

12. Felsenstein, J. 1989. PHYLIP-phylogeny inference package (version 3.2). Cladistics 5:164-166.

13. Feng, D.-F., and R. F. Doolittle. 1987. Progressive sequence alignment as a prerequisite to correct phylogenetic trees. J. Mol. Evol. 25:351-360.

14. Garnier, T., B. Canard, and S. T. Cole. 1991. Cloning, mapping, and molecular characterization of the rRNA operons of Clostridium. J. Bacteriol. 173:5431-5438.

15. Green, C. J., G. C. Stewart, M. A. Hollis, B. S. Vold, and K. F. Bott. 1985. Nucleotide sequence of the Bacillus subtilis ribosomal RNA operon, $r m B$. Gene 37:261-266.

16. Hartmann, R. K., J. Wolters, B. Kroeger, S. Schultz, T. Specht, and V. A. Erdmann. 1989. Does Thermus represent another deep eubacterial branching? Syst. Appl. Microbiol. 11:243-249.

17. Hensel, R., W. Dernharter, O. Kandler, R. M. Kroppenstedt, and E. Stackebrandt. 1986. Chemotaxonomic and moleculargenetic studies of the genus Thermus: evidence for a phylogenetic relationship of Thermus aquaticus and Thermus ruber to the genus Deinococcus. Int. J. Syst. Bacteriol. 36:444-453.

18. Hudson, J. A. 1986. The taxonomy and ecology of the genus Thermus. Ph.D. thesis. University of Waikato, Hamilton, New Zealand.

19. Hudson, J. A., H. W. Morgan, and R. M. Daniel. 1986. A numerical classification of some Thermus isolates. J. Gen. Microbiol. 132:531-540.

20. Hudson, J. A., H. W. Morgan, and R. M. Daniel. 1987. Thermus filiformis sp. nov., a filamentous caldoactive bacterium. Int. J. Syst. Bacteriol. 37:431-436.

21. Hudson, J. A., H. W. Morgan, and R. M. Daniel. 1989. Numerical classification of Thermus isolates from globally distributed hot springs. Syst. Appl. Microbiol. 11:250-256.

22. Janssen, P. H., L. E. Parker, and H. W. Morgan. 1991. Filament formation in Thermus species in the presence of some D-amino acids or glycine. Antonie van Leeuwenhoek 59:147-154.

23. Jones, C. J., H. W. Morgan, and R. M. Daniel. 1988. Aspects of protease production by a Thermus strain OK6 and other NZ isolates. J. Gen. Microbiol. 134:191-198.

24. Koyama, Y., T. Hoshino, N. Tomizuka, and K. Furukawa. 1986. Genetic transformation of the extreme thermophile Thermus thermophilus and other Thermus spp. J. Bacteriol. 166:338-340.

25. Kumano, M., N. Tomioka, K. Shinozaki, and M. Sugiura. 1986. Analysis of the promoter region in the $m n A$ operon from a blue-green alga, Anacystis nidulans 6301. Mol. Gen. Genet. 202:173-178.

26. Loginova, L. G., and L. A. Egorova. 1975. An obligately thermophilic bacterium Thermus ruber from Hot Springs in 
Kamchatka. Mikrobiologiya 44:661-665.

27. Maniatis, T., E. F. Fritsch, and J. Sambrook. 1982. Molecular cloning: a laboratory manual. Cold Spring Harbor Laboratory, Cold Spring Harbor, N.Y.

28. Messing, J. 1983. New M13 vectors for cloning. Methods Enzymol. 101:20-78.

29. Murzina, N., P. Vorozheikina, and N. Matvienko. 1988. Nucleotide sequence of Thermus thermophilus HB8 gene coding 16S rRNA. Nucleic Acids Res. 16:8172.

30. Oshima, T., and K. Imahori. 1974. Description of Thermus thermophilus (Yoshima and Oshima) comb. nov., a nonsporulating thermophilic bacterium from a Japanese thermal spa. Int. J. Syst Bacteriol. 24:104-112.

31. Pamilo, P., and M. Nei. 1988. Relationship between gene trees and species trees. Mol. Biol. Evol. 5:568-583.

32. Peek, K., P. H. Janssen, H. W. Morgan, and R. M. Daniel. 1990. Enhancement of in vitro stability and recovery of a proteinase produced by an extreme thermophile, p. 97-102. In P.-L. Yu (ed.), Fermentation technologies-industrial applications. Elsever Applied Science, London.

33. Rodrigo, A. G. Calculating the bootstrap test of monophyly. Int. J. Parasitol., in press.

34. Rodrigo, A. G., M. Kelly-Borges, P. R. Bergquist, and P. L. Bergquist. A randomization test of the null hypothesis that two cladograms are sample estimates of a parametric phylogenetic trees. N. Z. J. Bot., in press.

35. Saiki, T., R. Kimura, and K. Arima. 1972. Isolation and characterization of extremely thermophilic bacteria from hot springs. Agric. Biol. Chem. 34:2357-2366.

36. Saito, H., and K. Miura. 1963. Preparation of transforming deoxyribonucleic acid by phenol treatment. Biochim. Biophys. Acta 72:619-629.

37. Saitou, N., and M. Nei. 1987. The neighbour joining method: a new method for reconstructing phylogenetic trees. Mol. Biol. Evol. 4:406-425.

38. Sanderson, M. J. 1989. Confidence limits on phylogenetics: the bootstrap revisited. Cladistics 5:113-129.

39. Santos, M. A., R. A. D. Williams, and M. S. DaCosta. 1989.
Numerical taxonomy of Thermus isolates from hot springs in Portugal. Syst. Appl. Microbiol. 12:310-315.

40. Saravani, G. A. 1985. Caldolase: an alkaline serine protease from Thermus strain Tok3. Ph.D. thesis. University of Waikato, Hamilton, New Zealand.

41. Sharp, R. J., and R. A. D. Williams. 1988. Properties of Thermus ruber strains isolated from Icelandic hot springs and DNA:DNA homology of Thermus ruber and Thermus aquaticus. Appl. Environ. Microbiol. 54:2049-2053.

42. Stahl, D. A., and R. Amann. 1991. Development and application of nucleic acid probes, p. 205-248. In E. Stackebrandt and M. Goodfellow (ed.), Nucleic acid techniques in bacterial systematics. John Wiley \& Sons, Ltd., Chichester, United Kingdom.

43. Swofford, D. L. 1990. PAUP: phylogenetic analysis using parsimony, version 3.0. Complete program and manual. Illinois Natural History Survey, Champaign.

44. Swofford, D. L., and G. J. Olsen. 1990. Phylogeny reconstruction, p. 411-501. In D. M. Hills and C. Moritz (ed.), Molecular systematics. Sinauer Associates, Inc., Sunderland, Mass.

45. Weisberg, W. G., S. J. Giovannoni, and C. R. Woese. 1989. The Deinococcus-Thermus phylum and the effect of rRNA composition on phylogenetic tree construction. Syst. Appl. Microbiol. 11:128-134.

46. Wiley, E. O. 1981 . Phylogenetics: the theory and practice of phylogenetic systematics. Wiley Interscience, New York.

47. Williams, R. A. D. 1989. Biochemical taxonomy of the genus Thermus, p. 82-97. In M. S. DaCosta, J. C. Duarte, and R. A. D. Williams (ed.), Microbiology of extreme environments and its potential for biotechnology. Elsevier Applied Science, London.

48. Williams, R. A. D., and M. S. De Costa. 1991. The genus Thermus and related organisms, p. 3732-3744. In A. Balows, H. G. Trüper, M. Dworkin, W. Harder, and K.-H. Schleifer (ed.), The prokaryotes, 2nd ed. Springer-Verlag, Berlin.

49. Yanisch-Perron, C., J. Vieira, and J. Messing. 1985. Improved M13 phage cloning vectors and host strains: nucleotide sequences of the M13mp18 and pUC19 vectors. Gene 33:103-119. 